\title{
Integração vertical como estratégia de apropriação de valor: um estudo exploratório no canal de distribuição de produtos agrícolas
}

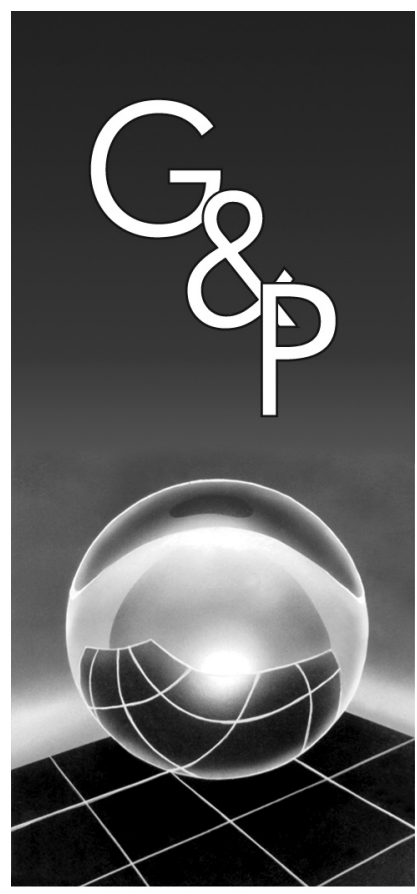

\author{
Vivian Lara dos Santos Silva \\ Fábio Rodrigues \\ Juliana Sannomya \\ Lizia Peres \\ Thainá Corvacho
}

\begin{abstract}
Resumo
Neste artigo, investiga-se a adoção de canais alternativos para a comercialização de produtos agrícolas como forma de atenuar o poder, cada vez maior, exercido pelas grandes redes varejistas. $O$ artigo investiga a decisão - e os efeitos daí decorrentes - de uma determinada empresa sediada no interior paulista, agrícola Pedra Branca, quanto à operacionalização verticalizada de uma butique de frutas, legumes e verduras (FLVs). Consciente dos novos padrões demandados pelo consumidor, a estratégia da empresa alvo do estudo foi combinar a oferta regular de produtos frescos, de qualidade intrínseca padronizada e preços atrativos, a um serviço diferenciado, baseado em um alto valor na experiência de compra. Esta estratégia fundamenta-se no anseio dos consumidores de, mais do que simplesmente adquirir produtos, experimentar sensações, as quais vividas em momentos de lazer exerceriam um grande poder de diferenciação. Realizou-se um estudo de caso baseado em entrevistas em profundidade semiestruturadas com diretores e gerentes da empresa. Como resultado, as evidências empíricas sugerem: 1) a verticalização (integração
\end{abstract} vertical) da atividade de comercialização como uma alternativa para a apropriação de valor da produção ao longo do canal de distribuição; e 2) o desafio da gestão do suprimento como requisito-chave para a adequada gestão do valor de uma marca. Considera-se oportuno lembrar, porém, que, em decorrência das limitações próprias da metodologia de estudos de caso, estas tais evidências devem ser entendidas como proposição a ser testada em trabalhos quantitativos futuros, ou mesmo melhor embasada via condução de estudos multicaso.

Palavras-chave: Varejo de alimentos. FLVs. Verticalização. Canais de distribuição.

\section{Introdução}

Nos últimos anos, como consequência de um acentuado processo de concentração que marcou o varejo mundial de alimentos, as redes supermercadistas vêm se beneficiando de um aumento na capacidade de barganha junto a seus fornecedores. No Brasil, a situação não foi diferente, aonde, em acréscimo, as grandes redes varejistas também vêm optando pela operacionalização de centrais próprias de compra de frutas, legumes e verduras (FLVs). Ao eliminar a figura dos intermediários do canal de distribuição, a exemplo da Companhia de Entrepostos e Armazéns Gerais de São Paulo (CEAGESP), os grandes varejistas beneficiam-se de um aumento de escala e, consequentemente, de um maior poder de compra junto aos produtores agrícolas, viabilizando reduções de custos, na ordem de 30\% (FAULIN; AZEVEDO, 2003).
Em face do exposto, o objeto deste artigo é investigar a busca, cada vez mais recorrente, de pequenos e médios produtores agrícolas pela definição de canais alternativos de distribuiçãocomo propósitodereduziropoderexercidopelas grandes redes varejistas na comercialização/distribuição de seus produtos. Em especial, o artigo investiga o estudo de caso da agrícola Pedra Branca, empresa sediada no interior do Estado de São Paulo, que apostou na operacionalização direta (verticalizada) de uma butique de frutas, legumes e verduras (FLVs).

$\mathrm{O}$ presente trabalho estrutura-se da seguinte forma. $\mathrm{Na}$ próxima seção, exibe-se uma revisão sobre o atual cenário da comercialização e distribuição de alimentos. Com base em evidências teóricas e empíricas de trabalhos recentes, na segunda seção, discute-se a inversão de poder regis- 
trada nas últimas décadas sobre o controle dos canais de distribuição (da indústria para o varejo) e o modo como os novos padrões demandados pelo consumidor podem ser explorados por parte dos produtores e processadores de alimentos como uma forma de reação ao poder detido pelas grandes redes varejistas. Na sequência, na terceira seção, discute-se a fundamentação teórica do estudo, avaliando o dilema inerente à estratégia de verticalização. $\mathrm{Na}$ quarta seção, apresentam-se a metodologia adotada, o caso da empresa agrícola Pedra Branca e os resultados. Encerrando o artigo, na quinta e última seção, apresentam-se as considerações finais e implicações gerenciais do caso a outras investidas similares.

\section{Os novos padrões de consumo e 0 peso das grandes redes varejistas na distribuição e comercialização de alimentos}

Os crescentes sinais do aumento da demanda por FLVs têm feito com que a padronização e a uniformidade da qualidade intrínseca do produto (coloração, tamanho, frescor, variedade, etc.) sejam cada vez mais exigidas pelo consumidor. É fato, porém, que a combinação pura de qualidade a preços atrativos não mais garante, a nenhum tipo de negócio, nem mesmo ao alimentar, uma vantagem competitiva sustentável - referindo-se a um diferencial competitivo dificilmente copiado (ou seja, sem custos ou no curto prazo) pela concorrência (ROSENBLOOM, 2002).

Entre os critérios imperativos demandados pelo consumidor, peso significativo cabe à praticidade, fato, ao menos em parte, decorrente do aumento da participação feminina no mercado de trabalho e da correria da vida moderna (GODOY, 2003). Atestando esta afirmação, os censos demográficos do IBGE revelam que, nos anos 50, as mulheres participavam com apenas $14,5 \%$ da população brasileira economicamente ativa. Nos anos 70, este índice ultrapassou a casa dos 20\%, abrindo os anos $2000 \mathrm{com}$ uma representatividade de $40 \%$ (LEÃO, 2005). Como reflexo dessa maior restrição de tempo, o consumidor vem valorizando o hábito de consumo por alimentos processados (seleção, lavagem, picagem, empacotamento, etc.) e por refeições realizadas fora de casa, o que tem aquecido o mercado nacional e internacional de food service. No Brasil, entre a década de 50 e os anos 2000, os gastos com alimentação fora de casa passaram de 7,5\% para $11,9 \%$. Não bastante, em 2005, um terço das refeições dos brasileiros residentes em metrópoles já ocorria em restaurantes, padarias e redes de fast food, estabelecimentos que, quando somados, totalizariam 1,3 milhão de unidades (BLECHER, 2002; GODOY, 2003). Incrementando o próspero mercado de refeições fora do lar, a indústria brasileira de alimentos teria destinado, no ano de 2005, o equivalente a $25 \%$ de sua produção, movimentando uma cifra superior a $\mathrm{R} \$ 38$ bilhões. Apenas para restaurantes, as vendas da indústria de alimentos foram de $\mathrm{R} \$ 8,9$ bilhões em 2005, o equivalente a $R$ \$ 1 bilhão a mais do que as cifras registradas em 2004 (BLECHER, 2006).

Em acréscimo à praticidade, Batalha, Lucchese e Lambert (2005) destacam outros requisitos entre os critérios imperativos demandados pelo consumidor, a saber: amabilidade da equipe de colaboradores do ponto comercial, promoções, sortimento, honestidade, portfólio de serviços prestados, acessibilidade, organização das prateleiras, limpeza, preços, animação do local, horários de funcionamento, rapidez do atendimento e qualidade intrínseca dos produtos (coloração, tamanho, frescor, variedade, etc.).

Outro importante trunfo sobre o processo de decisão de compra vem sendo a utilização do ponto de venda como uma espécie de palco, viabilizando a experiência de contato direto do consumidor com os produtos, com estímulo a seus sentidos (olfato, paladar, tato, visão e audição), transformando, assim, o ato da compra em uma experiência prazerosa, única e individual. Essa estratégia representa uma nova versão das lojas de departamentos nos moldes americanos e europeus, que, até os anos 50, entretinham os clientes com salões de chás e orquestras. Segundo Herzog (2005), esse reposicionamento se justifica em vista da nova era que marca a humanidade, a era das emoções, dos sonhos, em que os serviços marcantes são as experiências pessoais. Tal perspectiva ampara-se no que a literatura vem designando como "marketing de experiência" (PINE II; GILMORE, 1999), fundamentado em dois pilares: o primeiro, mais do que simplesmente adquirir produtos, as pessoas estariam dispostas a experimentar sensações; enquanto o segundo assevera que "experiências" vividas em momentos de lazer possuem um grande poder de aproximação (OLIVEIRA, 2007; SCHURMANN, 2005), portanto de diferenciação.

Ocorre, porém, que, por mais que pontos de venda diferenciados, em termos do ambiente e serviço, sejam peças importantes na conquista do consumidor, todos os investimentos são inevitavelmente colocados em xeque diante de eventual indisponibilidade do produto (irregularidade na entrega) ou, o que seria ainda pior, diante do não atendimento às condições de padronização requeridas pelo consumidor. Ou seja, o êxito da estratégia de diferenciação do ambiente por meio da criação de atmosferas de prazer e espaços nos quais os sentidos dos consumidores possam ser aguçados (sentir, emocionar-se, pensar, agir e relacionar-se) apenas deverá representar uma efetiva vantagem competitiva quando estruturado em investimentos continuados na gestão de todo o canal de distribuição, em termos do desenvolvimento de parcerias duradouras com 
fornecedores e agentes de distribuição e comercialização (COUGHLAN et al., 2002; ROSENBLOOM, 2002).

A interpretação dessa afirmação tem como foco um ponto em especial. Um canal de distribuição não deve ser entendido como uma mera alternativa para uma empresa que deseja fazer o melhor que pode no mercado. Nem tampouco deve ser interpretado como o resultado do esforço de um conjunto de empresas desconectas. Ao contrário, a eficiência do propósito do canal, isto é, a satisfação do consumidor por meio da criação de valor (COUGHLAN et al., 2002; ROSENBLOOM, 2002), depende da orquestração de toda a rede de organizações (NEVES, 2003), no sentido de os agentes envolvidos atuarem de maneira coordenada, compartilhando dos mesmos objetivos no que se refere à imagem do bem/serviço comercializado (BERMAN, 1996; LIMA-FILHO; SPROSSER, 2006), contribuindo, dessa forma, para a adequada satisfação do consumidor final.

Vislumbrando o ponto comercial como uma poderosa arma concorrencial de diferenciação e agregação de valor aos bens/serviços comercializados, produtores e processadores de alimentos deparam-se, contudo, com o maior poder detido pelos grandes grupos varejistas. A partir dos anos 70, o aumento da concorrência somado ao processo de concentração do varejo contribuiu para uma mudança de paradigma: de um meio físico para alcançar os consumidores, os setores primário e secundário passaram a ver a atividade de distribuição como importante à sua própria sobrevivência. Isso porque, não estar nas gôndolas de uma grande rede supermercadista representa uma perda de mercado estimada em 10\% (BATALHA; LUCCHESE; LAMBERT, 2005). O varejo tirou, assim, da indústria processadora, o controle sobre os canais de distribuição, passando a impor as regras no relacionamento comercial com maior capacidade de barganha (BATALHA; LUCCHESE; LAMBERT, 2005; BLECHER, 2002).

Não bastante, as grandes redes varejistas vêm ainda aumentando seu poder diante dos fornecedores via estratégia de verticalização do processo de compra de parte do mix de produtos, questão retratada em alguns estudos empíricos, como em Caleman et al. (2005), para o caso do suprimento de carne bovina, e Souza (2001) e Faulin e Azevedo (2003), quanto ao abastecimento de FLVs. De acordo com Souza (2001) e Faulin e Azevedo (2003), no passado recente, a comercialização de hortaliças, assim como de frutas, dava-se principalmente através das feiras livres, de maneira que o canal de distribuição revelava muitas falhas, que refletiam a precariedade dos sistemas de abastecimento e a falta de planejamento das cidades. Por outro lado, o baixo nível de renda da sociedade e o menor apelo pelo consumo garantiam a continuidade da comercialização sustentada pelas bases tradicionais. Mais recentemente, essa situação foi alterada, observando-se a queda da participação das feiras em razão do aumento do interesse dos supermercados na comercialização de produtos frescos - importante fator de diferenciação -, de forma que o varejo passou a representar um dos elos mais importantes na distribuição de alimentos perecíveis.

De fato, Faulin e Azevedo (2003) identificam que os supermercados já constituem o principal canal de distribuição de hortaliças na maioria das áreas metropolitanas brasileiras, com exceção de São Paulo, Belém e Belo Horizonte, locais onde o principal ponto de venda de hortaliças ainda são as feiras livres, sacolões, varejões e comboios - que, de acordo com Farina e Machado (2000), constituem uma espécie de minivarejões com uma única pequena loja para cada tipo de produto. Ao eliminar a figura dos intermediários do canal, a exemplo do CEAGESP, dada a decisão de operacionalização direta de centrais próprias de compra, os grandes varejistas foram beneficiados pelo aumento de escala e, consequentemente, por um maior poder de compra, viabilizando reduções de custos na ordem de $30 \%$.

Em decorrência desse cenário, as redes varejistas ganharam escala, o que se traduziu em maior poder de negociação com seus fornecedores e, consequentemente, na imposição de contrapartidas inviáveis em muitos casos. Além do preço, da pontualidade na entrega e da qualidade dos produtos, a comercialização por meio das grandes redes varejistas passou a ser subordinada a uma rotina de exigências de descontos para lançamentos, promoções, vendas em datas especiais, bonificações e contribuições usualmente conhecidas como "enxovais", referindo-se ao conjunto de mercadorias e benfeitorias que os fornecedores devem, gratuitamente, ofertar à rede varejista na inauguração de uma nova unidade (BATALHA; LUCCHESE; LAMBERT, 2005; BLECHER, 2002).

A problemática revela-se aqui definida. Por um lado, a existência de uma demanda que passou nos últimos anos a valorizar a regularidade de uma oferta variada e com qualidade padronizada, aliada a preços atrativos e praticidade em um ambiente diferenciado. Por outro lado, controlando o acesso - e a adequada satisfação - a essa demanda, tem-se cada vez mais um menor número de empresas, que, em decorrência de uma maior capacidade de barganha, passou a condicionar a participação dos fornecedores em suas gôndolas a pesadas contrapartidas. Por fim, não se pode omitir da análise os desdobramentos impostos por tal cenário ao pequeno varejo, em função das vantagens de custos inigualáveis às detidas pelas grandes redes de distribuição varejistas.

Como forma de reação, o pequeno varejo conta, todavia, com a possibilidade de transformar o que seria seu grande ponto falho (pequena escala) em um poderoso trunfo. Graças à maior proximidade com o consumidor, estabelecimentos de menor porte, quando bem explorados, devem revelar-se mais eficientes no atendimento aos novos padrões de consumo. Vantagens competi- 
tivas importantes podem ser exploradas por meio de uma melhor identificação das preferências dos consumidores e, assim, da oferta de um serviço customizado, favorecendo um maior valor à experiência de compra (DALLA COSTA; LIMA, 2005) e, consequentemente, a possibilidade de receber um preço premium. De olho nos ganhos potenciais decorrentes desse cenário, produtores agrícolas e processadores de alimentos passaram a buscar canais alternativos de distribuição, apostando: 1) na pulverização e fortalecimento das vendas diretas; 2) na aproximação com pequenos e exclusivos distribuidores/varejistas regionais; 3) no atendimento do mercado institucional e de food service; ou, ainda, 4) na operacionalização direta de pontos de venda, ou seja, a verticalização da atividade de comercialização dos produtos. A prática da verticalização da comercialização por parte de produtores agrícolas é o tema que a quarta seção procura ilustrar por meio da discussão do estudo de caso da empresa agrícola Pedra Branca.

\section{O dilema da "verticalização" ou integração vertical}

A verticalização caracteriza-se pela decisão organizacional em internalizar, no sentido de "tomar para si", o controle de estágios a montante ou a jusante do canal de distribuição. A escolha por tal estratégia de coordenação do canal impõe às organizações um clássico dilema. Por um lado, a escolha pela verticalização possibilita à firma um maior domínio sobre diferentes etapas de seu canal de distribuição e respectivo maior controle sobre ações conduzidas, viabilizando, dessa forma, uma maior eficiência na coordenação e gerenciamento da produção e/ou distribuição.

Resgatando o viés da economia dos custos de transação (WILLIAMSON, 1991), a verticalização possibilita um controle mais efetivo das transações por permitir ao responsável pela integração o exercício de um poder de fiat ("faça-se!"), pela manutenção dos direitos residuais de controle, favorecendo que a maior parte dos conflitos contratuais seja resolvida internamente, sem o uso do poder judiciário. Este aumento de controle, a partir da verticalização das atividades, torna-se necessário em vista do aumento das especificidades dos ativos empregados, de forma a minimizar a ação oportunista dos agentes envolvidos. Assim, quanto maior a especificidade dos ativos empregados em determinada transação, a adoção de uma estrutura de governança que tenda à hierarquia - e o ônus sobre os custos incorridos nessa decisão - passa a representar a opção mais eficiente, em termos da minimização dos custos transacionais, referindo-se aos custos de elaboração e negociação dos contratos, mensuração e fiscalização dos direitos de propriedade, monitoramento do desempenho e organização das atividades (CHEUNG, 1969).
Complementando essa discussão, Coughlan et al. (2002) considera que as decisões de integração vertical devem estar baseadas economicamente em termos de eficiência, ou seja, devem se concentrar em fatores que aumentem a renda e diminuam os custos ou as despesas gerais. De forma que a pergunta principal deve ser: a firma será mais eficiente, caso integre verticalmente? Essa indagação, para Besanko, Dranove e Shanley (2000), remete à idéia de que a firma apenas deve integrar verticalmente caso obtenha alguma vantagem competitiva em relação a seus concorrentes, como, por exemplo, a criação e captura de um valor maior do que o dos concorrentes (SOUZA, 2005). Sendo o conceito de valor entendido como a quantia pela qual os compradores estão dispostos a pagar pelos bens/serviços oferecidos pela firma, a criação de valor ocorre quando a combinação dos recursos utilizados na produção do respectivo bem/serviço gera um benefício - percebido pelo consumidor - superior aos custos incorridos (BESANKO; DRANOVE; SHANLEY, 2000; SOUZA, 2005).

Por outro lado, no entanto, a verticalização ou integração vertical nem sempre se caracteriza como a melhor opção, em decorrência justamente de seus custos fixos, por vezes dificilmente realocáveis em outras atividades. Outra nuance dos custos incorridos na verticalização refere-se aos "custos de aprendizado" no tocante ao gerenciamento de competências distintas das originalmente detidas pela empresa. Cautela especial deve, portanto, ser dada à estratégia de verticalização. Parte dos ganhos esperados podem ser perdidos frente à necessidade de a empresa ter que gerenciar competências organizacionais distintas de suas originais, incorrendo, por exemplo, em custos de aprendizado na utilização da nova estrutura de governança de coordenação do canal. Por exemplo, a competência originalmente detida pelos produtores e processadores de alimentos é a internalização da atividade produtiva, não devendo ser óbvios escolha e gerenciamento de um estabelecimento comercial.

\section{Resultados e discussão}

\subsection{Metodologia adotada}

Vislumbrando-se as vantagens enfatizadas por Jick (1983), utilizou-se da metodologia de estudos de caso (YIN, 2001) com o intuito de iluminar os elementos do contexto, trazendo à tona dados e evidências que outros métodos, em especial os quantitativos, não identificariam. Utilizou-se um roteiro de questões-chave que norteou as três entrevistas em profundidade conduzidas entre março e setembro de 2006, com diretores e gerentes da empresa. A entrevista em profundidade presta-se a desvendar as dimensões ou elementos envolvidos no fenômeno sob estudo e não a extensão quantificada com que tais 
elementos efetivamente ocorrem em uma dada população (MALHOTRA, 1996; PAVAN et al., 2001). Por meio do emprego de entrevistas em profundidade semiestruturadas procurou-se, assim, atenuar as tradicionais críticas à metodologia em questão (estudo de caso): abordagem intuitiva, sem a verificação de vieses resultantes de pontos de vista pessoais dos pesquisadores, com a falta de uma regra metodológica clara e bem definida, dificultando a replicação dos resultados (EISENHARDT, 1989; LAZZARINI, 1997).

\subsection{O caso da agrícola Pedra Branca}

A agrícola Pedra Branca foi fundada em $2001 \mathrm{com}$ o propósito econômico e social de desenvolver e comercializar tecnologia de ponta no controle operacional da produção hidropônica de FLVs, especialmente destinada a regiões dizimadas pela guerra civil na África.

A hidroponia é entendida como a ciência de cultivar plantas sem solo, na qual as raízes recebem uma solução nutritiva balanceada contendo água e todos os nutrientes essenciais ao desenvolvimento da planta. Sob a técnica da hidroponia, as raízes podem estar suspensas em meio líquido (NFT) ou apoiadas em substrato inerte, como areia lavada (LABHIDRO, 2006). Vislumbrou-se, assim, a oportunidade de negócio dedicada à concepção e comercialização de programas computacionais "amigáveis" que viabilizassem o controle integral das operações de estufas hidropônicas, facilitando o gerenciamento e controle de sua produção.

A consagração do empreendimento deparava-se, contudo, com a necessidade de testes pilotos. Optou-se, então, pela construção no município de Pirassununga, SP, de uma estufa hidropônica piloto dedicada à produção de hortaliças. A produção decorrente dos testes experimentais era, originalmente, escoada via tradicionais canais de distribuição: restaurantes e supermercados da região de Pirassununga. Mais do que restringir suas atividades à pesquisa, a agrícola Pedra Branca passou, assim, a conciliar suas atividades de $P \& D$ às atividades de comercialização.

A estrutura fechada das estufas empregadas e a utilização de iscas naturais na captura de pragas, além de viabilizar a regularidade e a estabilidade da oferta, em termos da variedade, tamanho e grau de maturidade, permite uma utilização mínima de defensivos agrícolas. Ou seja, embora não seja entendida como orgânica, a produção em estufas contribui para a demanda cada vez mais recorrente do consumidor por uma alimentação mais natural. Em acréscimo, a produção em hidroponia contribui para uma maior durabilidade das hortaliças, em média três vezes maior do que as obtidas sob técnicas tradicionais de cultivos. Essa superior qualidade comparativa dos produtos hidropônicos impulsionou a possibilidade de a empresa explorar os diferenciais de seus produtos por meio da criação de uma identidade própria com o consumidor, via concepção de uma marca e sua comercialização em gôndolas diferenciadas nos supermercados.

Ocorre, porém, que tais planos de diferenciação na ponta da gôndola esbarraram nas pesadas condições financeiras exigidas por parte das redes varejistas, culminando num repensar sobre as formas de distribuição e comercialização a serem empregadas. Esse atrito com as redes varejistas foi decisivo para a decisão de verticalização do canal de distribuição via operacionalização de uma butique de FLVs na cidade de Pirassununga.

Nascia, assim, no ano de 2005, com um conceito diferenciado e inovador de negócio, a Vivante!, cujo slogan procura explorar/resgatar os benefícios-chave da técnica produtiva da hidroponia: "sabor com vida, todo dia!". Mais do que isso, consciente dos novos padrões demandados pelo consumidor, a Vivante! combina a oferta regular de produtos frescos, com qualidade intrínseca padronizada e preço atrativo a um serviço diferenciado em um alto valor na experiência de compra. Graças à forma como os produtos são expostos na loja - limpo e fresco, preservando sua raiz embebida em água em canaletas, mantendo o frescor e os aspectos da planta como na fazenda -, o consumidor é atraído pela oportunidade de desfrutar da sensação de colher seus produtos. Procura-se resgatar as sensações e experiências passadas, da bucólica experiência do campo, de sua tranquilidade e qualidade de vida, forte anseio da maior parte da população inviabilizada pela agitação da vida moderna.

Menos de dois anos depois de sua inauguração, o sucesso das atividades da primeira unidade Vivante! pode ser medido, qualitativamente, pelos novos rumos registrados na agrícola Pedra Branca. As atividades de P\&D de programas computacionais dedicados ao gerenciamento e controle operacional de estufas hidropônicas deixaram de representar o core business da empresa. A estufa experimental é ainda mantida, e avanços na difusão e comercialização do software vêm sendo continuamente observados, em especial com empresários de Angola, na África. Todavia, as atividades da estufa experimental passaram a ser desenvolvidas junto a outras 14 estufas de caráter comercial, dedicadas à produção de hortaliças. Avanços também na produção de frutos, em particular tomate, começam a ser registrados. Esta estrutura viabiliza uma produção média de 5.000 unidades de folhas por ciclo de 40 dias, produção dedicada ao abastecimento da Vivante!.

\subsection{Agregação de valor pela integração vertical}

Ao integrar verticalmente a jusante, a agrícola Pedra Branca estaria melhor capturando o valor sobre sua produção ao longo do canal? As evidências verificadas nas entrevistas sugerem que sim. 
Comparativamente aos preços praticados pela concorrência, a agrícola comercializa seus produtos em sua butique Vivante! a um preço médio superior a 50\% do preço de mercado. É fato que tal diferencial de preços deve ser associado aos maiores custos fixos e variáveis incorridos na operacionalização verticalizada de sua loja, bem como aos maiores custos comparativos relacionados ao seu sistema hidropônico diferenciado. Os materiais empregados, tanto nas canaletas, onde se dá o cultivo, quanto na estrutura propriamente dita das estufas e no revestimento - as estufas são completamente fechadas -, implicam, inevitavelmente, em maiores investimentos e, portanto, em maiores custos, os quais, porém, são justificados pela empresa em decorrência do incremento da vida útil das estufas e da possibilidade de utilização de menor volume de defensivos agrícolas.

Todavia, o adicional de preços praticado pela empresa em sua butique de FLVs também deve ser atribuído ao atendimento aos "novos padrões de consumo": oferta regular de produtos frescos, de qualidade padronizada, em um ambiente diferenciado, baseado em alto valor na experiência de compra. Em acréscimo, a Vivante! também proporciona a seus consumidores uma melhor relação custo-benefício, pois, quando armazenadas com raiz na geladeira, as hortaliças hidropônicas chegam a manter suas características sensórias e organolépticas por um período duas vezes superior ao dos produtos convencionais. Ao melhor satisfazer os anseios de seu consumidor, em um ponto de venda próprio, a empresa estaria, de fato, capturando a maior parte do valor gerado em sua produção, expresso no recebimento de um preço premium. Entendendo e valorizando tais diferenciais, o leque de consumidores Vivante! não se restringe às classes econômicas de maior poder aquisitivo. Diferentemente disso, cada vez mais, percebe-se também uma significativa participação de consumidores da classe C.

Resultados conclusivos sobre a hipótese de apropriação de valor por parte da agrícola Pedra Branca dependem, contudo, da condução de análises específicas. De acordo com Souza (2005), dois diferentes métodos podem ser empregados no intuito de adequadamente responder a essa questão: 1) análise do valor adicionado; e 2) investigação dos preços praticados por cada membro da cadeia de valor. $\mathrm{O}$ primeiro método permite estimar o valor adicionado ao produto final por cada uma das etapas de produção, até chegar a seu preço de mercado. Relatórios industriais e coleta de dados primários, junto aos membros do canal de distribuição, são fontes importantes para a análise de valor adicionado. Por sua vez, o segundo método caracteriza-se por um indicador de como as rendas são divididas entre todos os segmentos participantes do canal. Este método pode ser calculado por meio dos preços praticados por cada membro, ou, ainda - considerando-se canais internacionais -, com base na análise pelos países e regiões, por meio do uso de dados de importação e exportação, para conseguir estimar a participação de cada etapa necessária desde a produção dos insumos e matérias-primas até a distribuição e comercialização propriamente ditas (SOUZA, 2005).

\subsection{O desafio da gestão do suprimento como requisito-chave à adequada gestão do valor de uma marca}

O êxito alcançado nos primeiros anos de atividade da Vivante!, em especial, considerando-se as limitações impostas pelas características econômicas e sociais de uma cidade do porte de Pirassununga, com uma população estimada em 60 mil habitantes, vem impulsionando a aposta da empresa na diversificação de suas atividades, direcionada à operacionalização de uma rede de butiques.

Vale resgatar que, a despeito das atividades de P\&D de softwares computacionais de gerenciamento e controle de estufas, as atividades comerciais da agrícola reportam-se, exclusivamente, à produção de hortaliças e frutos. Acontece, porém, que a adequada atração e fidelização do consumidor passa, obrigatoriamente, pela regularidade de um mix variado de produtos sob padrões de qualidade intrínseca previamente estipulados pelo consumidor. Nesse sentido, a agrícola justifica a diversificação de suas atividades em novos projetos, não necessariamente restritos a produtos hortícolas. Já é fato, por exemplo, a linha Vivante! de minimamente processados. Em acréscimo, a agrícola investe no plantio de abacaxi gomo de mel e na verticalização da produção de mudas de tomate. Há outros projetos na produção de forragem hidropônica, a ser empregada em suas estufas, passando pela criação de caprinos e ovinos e pela criação de peixes. Ocorre, contudo, que, mesmo com os novos negócios, a agrícola não consegue atender ao volume total comercializado pela Vivante!. Ou seja, um importante gargalo de crescimento da Vivante! refere-se às limitações de produção da agrícola.

Sem considerar as limitações de espaço da atual sede rural da agrícola, a possibilidade de expansão de seu volume de produção esbarra nos custos incorridos em um processo adicional de beneficiamento da água para utilização nas estufas. A água utilizada pela agrícola Pedra Branca é originária de poço artesiano perfurado na própria fazenda. Todavia, sua utilização depende de um processo adicional de beneficiamento em que o excedente de cloreto de sódio da água é retirado por um processo de osmose reversa. Como as atividades iniciais da agrícola diziam respeito à $\mathrm{P} \& \mathrm{D}$ de softwares de gestão e controle de estufas, a decisão da localização geográfica da propriedade rural não foi baseada em estudos prévios sobre a qualidade da água, particularmente no tocante aos níveis de cloreto de sódio, grave impedimento às atividades comerciais de uma estufa hidropônica. Embora a vazão de seu lençol freático atenda ao volume necessário 
para a ampliação do número de estufas, os custos incorridos na ampliação desse processo de beneficiamento da água tornam inviáveis a ampliação das atividades da atual sede da agrícola.

Não bastante, outro importante gargalo de crescimento da Vivante! não pode ser marginalizado. A técnica produtiva da hidroponia atenua um dos principais problemas reportados aos produtos alimentares: a sazonalidade da oferta. A hidroponia contribui significativamente para a redução da influência de intempéries climáticas, favorecendo o planejamento e o controle da produção. Acontece, porém, que, ao contrário da maioria dos produtos alimentares, o consumo de FLVs, em especial de hortaliças, distingue-se por uma expressiva sazonalidade. Diferentemente do que ocorre no verão, quando as altas temperaturas estimulam o consumo de alimentos leves, no inverno, por questões que remontam ao instinto de sobrevivência, nosso corpo naturalmente demanda alimentos "pesados", gordurosos. Mesmo considerando o fato de o inverno brasileiro não ser rigoroso, afirmação especialmente verdadeira para o Estado de São Paulo - caso da região de Pirassununga -, em seu primeiro verão a Vivante! registrou uma perda diária de $10 \%$ da produção total de hortaliças da agrícola. A elevada perecibilidade dos hortifrutis dificulta seu acondicionamento sem danos sensoriais, obrigando que parte da produção seja escoada por canais alternativos para minimizar os prejuízos. Mesmo diante desse cenário, a agrícola não mostrou interesse em retomar a distribuição de seus produtos via varejo tradicional, dadas as dificuldades de negociação com as redes varejistas, expressas, por exemplo, na inexistência de contrato garantindo a aquisição e o adequado comprometimento na exploração do conceito Vivante!. A solução momentânea vem sendo a utilização dos frutos na produção de molhos comercializados na butique e a doação de folhas para instituições de caridade, além da utilização do excedente na alimentação de sua equipe de colaboradores.

O desafio central sofrido pela agrícola em termos da adequada gestão do suprimento pode assim ser resumido: as oscilações no consumo de hortaliças versus as restrições no atendimento do volume e sortimento comercializado em sua butique Vivante!. Por ora, a agrícola vem buscando no CEAGESP, o complemento do volume e sortimento do mix de produtos comercializados na Vivante! Estratégia, porém, que revela profundas implicações em termos da regularidade da qualidade ofertada e dos custos incorridos no transporte. A alternativa idealizada pela empresa foi investir na construção de um entreposto de compra e de distribuição de FLVs, com atuação na região de Pirassununga. A agrícola passaria, assim, a exercer a função de coordenação de produtores - não necessariamente hidropônicos - de FLVs da região, visando ao atendimento de um sortimento mínimo a sua unidade Vivante! bem como, em épocas de queda de consumo, ao melhor escoamento de sua produção via outros negócios alimentares da região, referindo-se a pequenos e médios estabelecimentos supermercadistas além de restaurante, bares, etc. Ou seja, a agrícola, além de executar atividades de varejo, assumiu agora operações de atacado de FLV.

O desafio imposto à agrícola quanto à adequada gestão do suprimento da Vivante! parece, contudo, distante de ter sido equacionado. A despeito das atividades do entreposto, ainda se levantam dúvidas quanto às garantias na regularidade da qualidade ofertada. Uma marca deve sinalizar ao consumidor uma informação valiosa no processo de decisão de compra. Sendo uma informação, a marca apenas terá valor se a organização conseguir garantir ao seu consumidor que bem/serviço "é - e o mais importante, que ele permanecerá - uniformemente bom ao longo do tempo" (BARZEL, 1982). De fato, os consumidores tendem a comprar uma marca conhecida, pois se sentem confortáveis com o que lhes é familiar. Uma marca reconhecida deverá, assim, ser frequentemente selecionada diante de uma outra, desconhecida. Ser conhecida é particularmente importante para que ela seja considerada uma alternativa de compra (AAKER, 1998). Afirmação que reforça significativamente a necessidade, no caso dos produtos alimentares, de uma visão sistêmica: coordenação de todo o canal de distribuição.

Azevedo (2001) afirma que a qualidade dos insumos é um ponto de referência quando se deseja fixar uma marca no mercado. Na ponta final do canal, existe um consumidor disposto a pagar mais por um produto de maior qualidade; e esse consumidor só o fará se a qualidade prometida for facilmente perceptível, ou se alguma informação adicional lhe indicar que o produto está associado a uma marca forte e realmente de alta qualidade. Essa discussão revela-se particularmente verdadeira no caso da investida da agrícola no varejo de alimentos sob um conceito tão diferenciado de negócio. A concepção de uma rede de estabelecimentos sob a marca Vivante! majora ainda mais o desafio da uniformidade da informação transmitida pela marca, implicando na identificação de parceiros que, mais do que capital físico, compartilhem dos mesmos valores e filosofias do grupo. Considerados estes requisitos, a ambição de uma rede de butiques Vivante! parece ser mais factível via verticalização do suprimento por parte da agrícola: caberia a ela o controle sobre a produção, podendo se valer de parceiros exclusivamente na gestão e controle operacional das unidades, via, por exemplo, formato de franquias. Todavia, um último e importante gargalo relacionado ao suprimento aparece: custos logísticos devem inviabilizar uma maior pulverização da rede rumo às grandes cidades de São Paulo, a exemplo da própria capital bem como de outras cidades, como Campinas. 


\section{Considerações finais e implicações gerenciais}

Este estudo aborda a prática da adoção de canais alternativos para a distribuição de produtos agrícolas, com a finalidade de atenuar o expressivo poder exercido pelas grandes redes varejistas. Em especial, o estudo enfoca o lado dos produtores agrícolas, ao investigar as oportunidades e os desafios impostos à investida da agrícola Pedra Branca na operacionalização de uma butique própria de FLVs sob um diferenciado conceito de negócio. Representando um primeiro diagnóstico da agrícola Pedra Branca, o estudo mostra: 1) a verticalização da atividade de comercialização como uma alternativa de apropriação de valor da produção por parte da indústria de alimentos e produtores agrícolas; e 2) o desafio da gestão do suprimento como requisito-chave à adequada gestão do valor de uma marca.

Sendo a mostra pequena e estatisticamente não representativa, as evidências levantadas no estudo de caso devem ser entendidas como proposições que mereçam ser testadas ou, mesmo, um melhor embasamento em trabalhos futuros, não podendo, assim, ser generalizadas ou extrapoladas para outras situações. Contudo, independentemente dos avanços necessários no intuito de dar melhor robustez aos resultados obtidos, as evidências empíricas proporcionadas pelo caso trazem importantes implicações gerenciais para pequenos e médios produtores agrícolas e processadores de alimentos, no anseio de atenuar o poder cada vez maior exercido pelas grandes redes varejistas.

Graças à maior proximidade entre cliente e vendedor, inata aos estabelecimentos de menor porte, vantagens competitivas importantes podem ser exploradas por meio da melhor identificação das preferências dos consumidores. O pequeno varejo conta, portanto, com a possibilidade de transformar o que seria seu grande ponto falho - pequena escala - em um trunfo contra as grandes redes varejistas: a atração e a fidelização do consumidor por meio do melhor atendimento a seus anseios, ou seja, oferta regular de produtos frescos, de qualidade intrínseca padronizada e preços atrativos a um serviço diferenciado, baseado em um alto valor na experiência de compra. De olho nos potenciais ganhos desse cenário, produtores e processadores de alimentos passam a buscar canais alternativos de distribuição, como, por exemplo, a aposta na verticalização (integração vertical) da comercialização e distribuição de seus produtos e serviços.

A escolha pela verticalização não deve, porém, ser entendida como uma solução fácil e imediata, ao impor às organizações o equacionamento de um clássico dilema. Se por um lado garante à empresa responsável pela verticalização um maior domínio sobre diferentes etapas do canal de distribuição - e maior controle sobre ações nelas conduzidas -, viabilizando uma maior eficiência na coordenação e gerenciamento da produção e/ou distribuição, por outro internaliza os custos incorridos, os quais, muitas vezes, não podem ser facilmente realocados em outras atividades. Parte desses custos pode revelar-se, inclusive, decorrente da necessidade de a empresa ter que gerenciar competências organizacionais distintas das suas originais, incorrendo, assim, em maiores custos de aprendizado na utilização da nova estrutura de governança de coordenação do canal.

A competência originalmente detida pelos produtores e processadores de alimentos é a internalização da atividade produtiva, não devendo ser óbvia a escolha pelo controle da comercialização de seus produtosv uma vez que custos relevantes de aprendizado deverão ser observados. Sem deixar de ignorar que a verticalização da comercialização impõe ainda o desafio de um melhor gerenciamento do suprimento, com a finalidade de preservar a capacidade da marca em sinalizar - uniformemente - a seu consumidor que o bem/serviço "é - e o mais importante, que ele permanecerá - uniformemente bom ao longo do tempo" (BARZEL, 1982).

Como agenda de pesquisa, o presente artigo deixa, em especial, a proposta para estudos voltados ao teste da hipótese da verticalização como alternativa à apropriação de valor. O caso da agrícola sugere, por fim, outros temas para futuros trabalhos, como a investigação dos limites da firma - até quando crescer: inovar sem limites deve sempre representar a melhor estratégia, sobretudo crescendo de maneira tão diversificada e verticalizada? Quais seriam as oportunidades e ameaças, referindo-se também aos riscos, de tal posicionamento estratégico? 


\title{
Alternative marketing channels in order to attenuate the power of retail chains: Agrícola Pedra Branca case study
}

\begin{abstract}
This paper aims to analyze the search for alternative marketing channels of industry and rural producers in order to attenuate the power of retail chains over the sale of products and services. In special, we focus on the rural producers' perspective investigating the decision of Agrícola Pedra Branca in operating a company-owned outlet of FLVs. In face of the new consumer demands, Agrícola Pedra Branca joins the regular offer of fresh products, standard quality, and good prices with marketing experience principles: more than shopping new products, consumers are looking for new experiences, which when to take effect in leisure time should give a high power of approach, and so an efficient base to a differentiation process. In this study, the case study methodology including semi-structured interviews with Agricola Pedra Branca's directors and managers was used. The results, suggest: 1) verticalization as an alternative to value appropriation along the marketing channel; and 2) supply management as an indispensable requisite to the adequate brand name value valorization and maintenance. Nevertheless, due to limitations of the case study these results should be understood as propositions to future studies.
\end{abstract}

Key-words: Food retail. FLVs. Hierarchy. Marketing channels.

\section{Referências bibliográficas}

AAKER, D. A. Brand equity: gerenciando o valor da marca. São Paulo: Negócio Editora, 1998. 309 p.

AZEVEDO, P. F. Comercialização de produtos agroindustriais. In: BATALHA, M. O. (Coord.). Gestão agroindustrial. 2 ed. São Paulo: Atlas, 2001. Cap. 2, p. 64-99.

BATALHA, M. O.; LUCCHESE, T.; LAMBERT, J. L. Hábitos de consumo alimentar no Brasil: realidade e perspectivas. In: BATALHA, M. O. (Coord.). Gestão do agronegócio: textos selecionados. São Carlos: Edufscar, 2005. Cap. 2, p. 28-84.

BARZEL, Y. Measurement cost and the organization of markets. Journal of Law and Economics, v. 25, p. 27-48, Apr. 1982.

BERMAN, B. Marketing channels. New York: John Wiley and Sons, 1996. 663 p.

BESANKO, D.; DRANOVE, D.; SHANLEY, M. Economics of strategy. New York: John Wiley \& Sons, 2000.

BLECHER, N. A ditadura do varejo. Disponível em $<$ http://portalexame.abril.com.br/edicoes/768/empresas/ conteudo_18820.shtml>. Acesso em: 03 Ago. 2005.

BLECHER, N. Eles têm apetite de investidor. Revista Exame, 07 de junho de 2006.

CALEMAN, S. M. Q. et al. Organic beef in Brazil: Consumer profile and marketing strategies. In: ANNUAL WORLD FOOD AND AGRIBUSINESS CONGRESS, 15, 2005, Chicago. Proceedings [Eletronic]... Chicago/USA: IAMA, 2005. Disponível em: <http://www.ifama.org/tamu/ iama/conferences/2005conference/Papers\&Discussions/1159_ Paper_Final.pdf >. Acesso em: 12 Fev. 2009.

COUGHLAN, A. T. et al. Canais de marketing e distribuição. 6 ed. Porto Alegre: Bookman, 2002. p. 411-437.

CHEUNG, S. N. S. The theory of share tenancy. Chicago: The University of Chicago Press, 1969. 169 p.

DALLA COSTA, A. J.; LIMA, R. C. A estrutura concorrencial no setor supermercadista: o caso curitibano a partir da década de 1990. In: EVINCI, 13, 2005. Resumos... Curitiba: Editora da UFPR, 2005. v. 1, p. 345-345.

EISENHARDT, K. M. Building theories from case study research. Academy of Management Review, v. 14, n. 4, p. 532-550, 1989.
FAULIN, E. J.; AZEVEDO, P. F. Distribuição de hortaliças na agricultura familiar: uma análise das transações. Informações Econômicas, v. 33, n. 11, 2003.

GODOY, R. C. B. Mercado para produtos minimamente processados. 2003. Disponível em: <http://www. portaldoagronegocio.com.br>. Acesso em: 10 Abr. 2006.

HERZOG, A. N. Deixe o consumidor experimentar: num movimento de renovação, o varejo tradicional se transforma numa espécie de parque de diversões para os consumidores. Revista Exame, 17 de novembro de 2005.

JICK, T. D. Mixing qualitative and quantitative methods: triangulation in action. In: MAANEN, J. V. (Ed.). Qualitative methodology. Newbury Park: SAGE Publications, 1983

LABHIDRO: Laboratório de agricultura irrigada e hidroponia da Universidade Federal de Santa Catarina. Disponível em: www.labhidro.cca.ufsc.br. Acesso em: 06 Abr. 2006.

LAZZARINI, S. G. Estudos de caso: aplicações e limites do método. In: FARINA, E. M. M. Q. Estudos de caso em agribusiness. São Paulo: Pioneira, 1997.

LEÃO, E. A. Uma análise da fecundidade no Brasil. Uberlândia: Instituto de Economia da Universidade Federal de Uberlândia, 2005. (working paper). Disponível em: http://www.pet.ie.ufu. br/paper\%202005.doc . Acesso em: 26 Mar. 2007.

LIMA FILHO, D. O.; SPROESSER, R. L. Setor Agronegócio: a mola mestra da balança comercial. In: Barrizzelli, N.; Santos, R. C. (Org.). Lucratividade pela inovação: como eliminar ineficiências nos seus negócios e na cadeia de valor. 1 ed. Rio de Janeiro: Ed. Elsevier, 2006.

MALHOTRA, N. Pesquisa de marketing: uma orientação aplicada. 3 ed. Porto Alegre: Bookman, 2001. 719 p.

NEVES, M. F. Canais de distribuição. In: NEVES, M. F.; CASTRO, L. T. Marketing e estratégia em agronegócios e alimentos. São Paulo: Atlas, 2003. Cap.11, p. 224-249.

NEVES, M. F.; CASTRO, L. T. Comportamento do consumidor de alimentos. In: NEVES, M. F.; CASTRO, L. T. Marketing e estratégia em agronegócios e alimentos. São Paulo: Atlas, 2003. Cap.3, p. 73-87. 
OLIVEIRA, J. C. V. Marketing da experiência. 2007. Disponível em<http://www.sebraesp.com.br/principal/abrindo $\% 20$ seu $\% 20$ neg\% C3\%B3cio/produtos\%20sebrae/artigos/listadeartigos/ marketing_experiencia.aspx>. Acesso em: 26 Mar. 2007.

PAVAN, T. A. et al. O Processo de compra de suco de laranja por varejistas. In: CONGRESSO DA SOCIEDADE BRASILEIRA DE ECONOMIA E SOCIOLOGIA RURAL - Sober, 2001. Anais...

PINE II, B. J.; GILMORE, J. H. O espetáculo dos negócios: the experience economy. Rio de Janeiro: Campus, 1999.

ROSENBLOOM, B. Canais de marketing: uma visão gerencial. São Paulo: Atlas, 2002. p. 23-157.

SCHURMANN, P. Marketing de experiência. Gazeta Mercantil, caderno A, Nov. 2005. Disponibilizado em: <http://www. appribeirao.com.br/artigos.php?id=10>. Acesso em: 26 Mar. 2007.

SOUZA, R. C. As estruturas de governança dos canais de comercialização de frutas, legumes e verduras no município de São Carlos, Estado de São Paulo. Informações Econômicas, v. 31, n. 11, p. 26-31, 2001.

SOUZA, R. C. Uma investigação sobre o segmento produtor de manga e uva in natura em sua inserção na cadeia de valor global. São Paulo, 2005. 197 p. Tese (Doutorado em Engenharia de Produção), Escola Politécnica da Universidade de São Paulo.

WILLIAMSON, O. E. Comparative economic organization: the analysis of discrete structural alternatives. Administrative Science Quarterly, v. 36, p. 269-296, 1991.

YIN, R. K. Estudo de caso: planejamento e métodos. 2 ed. Porto Alegre: Bookman, 2001.

\section{Sobre os autores}

\section{Vivian Lara dos Santos Silva}

Departamento de Engenharia de Alimentos ZEA-FZEA, Faculdade de Zootecnia e Engenharia de Alimentos, Universidade de São Paulo-USP, Av. Duque de Caxias Norte, 225 CEP 13635-900 Pirassununga, SP, e-mail: vivianlara@usp.br

\section{Fábio Rodrigues}

Engenheiro de Alimentos, Departamento de Engenharia de Alimentos ZEA-FZEA, Faculdade de Zootecnia e Engenharia de Alimentos, Universidade de São Paulo-USP, Av. Duque de Caxias Norte, 225 CEP 13635-900 Pirassununga, SP

\section{Juliana Sannomya}

Engenheira de Alimentos, Departamento de Engenharia de Alimentos ZEA-FZEA, Faculdade de Zootecnia e Engenharia de Alimentos, Universidade de São Paulo-USP, Av. Duque de Caxias Norte, 225 CEP 13635-900 Pirassununga, SP

\section{Lizia Peres}

Engenheira de Alimentos, Departamento de Engenharia de Alimentos ZEA-FZEA, Faculdade de Zootecnia e Engenharia de Alimentos, Universidade de São Paulo-USP, Av. Duque de Caxias Norte, 225 CEP 13635-900 Pirassununga, SP

\section{Thainá Corvacho}

Graduanda em Engenharia de Alimentos,

Departamento de Engenharia de Alimentos ZEA-FZEA, Faculdade de Zootecnia e Engenharia de Alimentos, Universidade de São Paulo-USP, Av. Duque de Caxias Norte, 225 CEP 13635-900 Pirassununga, SP

Agradecimentos: Para encerrar, agradecemos à FAPESP o imprescindível apoio concedido às atividades do Grupo de Estudos e Pesquisas em Estratégia e Coordenação Vertical da Faculdade de Zootecnia e Engenharia de Alimentos da Universidade de São Paulo, Campus de Pirassununga (GEPEC/FZEA-USP). Agradecemos, também, ao valioso suporte e oportuna sinergia advindos dos seminários e reuniões do GEAGRO (Grupo de Estudos e Pesquisa em Empreendedorismo e Gestão do Agronegócio) e UNITECEX (Centro de Inovação Tecnológica e Extensão Universitária). Da mesma forma agradecemos, aos dirigentes e funcionários da empresa alvo deste estudo, a solícita atenção e disponibilização de informações. Deve-se ressaltar, porém, que este artigo não reflete a opinião oficial da empresa, cabendo aos autores total responsabilidade, inclusive, sobre eventuais falhas. Nossos agradecimentos, por fim, aos revisores da Revista Gestão \& Produção por seus valiosos comentários, bem como ao Prof. Dr. Eurípides Alves da Silva (ex-Diretor da UNESP/SJRP, atualmente Assessor Acadêmico da Reitoria da UNIRP) e à Profa. Dra. Roberta de Castro Souza (Departamento de Engenharia de Produção do Centro Universitário da FEI) pelas competentes e criteriosas leituras das versões que antecederam a finalização deste trabalho. 